\title{
8
}

\section{EXPERIMENTAL INNOVATION IN MUSEUMS: ENCOURAGING CREATIVITY, BUILDING CONFIDENCE AND CREATING SOCIAL VALUE}

\author{
Haitham Eid
}

Research and development (R\&D) is recognised as a legitimate pathway for innovation in the for-profit and nonprofit sectors. It is the systematic process by which organisations develop new or enhance existing products or services. In the private sector, most firms have dedicated departments charged with managing the R\&D process. These departments consist of specialised teams with diverse expertise, including scientists, technologists and designers. While the typical organisational structure in museums does not encompass a permanent R\&D department, museums apply R\&D through ad-hoc teams, created to oversee and manage specific innovation projects. Upon delivering results of the innovation, these teams are dissolved, allowing each team member to continue his/her regular assignments in the museum (or engage in a different innovation project with a different team). For the sake of clarity, museum innovation is defined as 'the new or enhanced processes, products or business models by which museums can effectively achieve their social and cultural mission' (Eid, 2016).

Based on this definition, let us take the process of creating an innovative exhibition as an example (with the acknowledgement that not every exhibition is considered innovative). The process starts by assembling a team, which in most cases consists of a museum curator, designer, museum educator, registrar, technologist and project manager. From the ideation and conceptualisation process throughout the design and delivery phases, the team members, each of whom brings to the project a crucial set of expertise, meet regularly and work closely with each other. After the opening of the exhibition, the team is dissolved until the next innovation project is decided.

The traditional R\&D model has been historically effective in facilitating and managing innovation. However, this model is now being challenged, as argued by Larry Schmitt, co-founder and managing partner of the management consulting firm Inovo: 'In today's environment, $\mathrm{R} \& \mathrm{D}$ is no longer sufficient. What is needed 
is an Innovation System that is much more than traditional R\&D. It is a profound reimagining of the traditional functions of Strategy, R\&D and Business Development' (Schmitt, 2016). One of the strategic disadvantages of R\&D is the isolation of the innovation process in specific departments or teams, distancing it from the rest of the organisation and, more importantly, from the end-user. Additionally, the fast development in technology and the rapid change in customers' demands and expectations stipulate a more agile approach to innovation. The traditional R\&D model, on the other hand, is a lengthy process that can provide inaccurate results about the viability of the innovation being sought, which is known as false-negatives or false-positives. As such, innovation practitioners have begun to look at experimental innovation as a novel way to meet these new challenges.

In addition to the previous factors, museums are expected to take a more significant role in addressing contemporary social and environmental issues, a challenge that requires innovative thinking and profound reflections on how museums approach their work. In this context, experimental innovation, as discussed below, can provide a platform to explore new concepts and realise systematic change. More specifically, this chapter regards experimentation as a core organisational quality for innovation. If encouraged and rewarded across the museum, experimentation provides a more decentralised approach to innovation, where everyone in the museum is given the opportunity, even at a small scale, to explore and apply new ideas. This is different, as discussed earlier, from traditional $\mathrm{R} \& \mathrm{D}$, which is carried out by specialised teams (whether they are part of a permanent department or an ad hoc) and isolates the innovation process from the rest of the organisation.

\section{Experimental innovation}

Experimental innovation is a fairly new concept with no clear definition. Hampel et al. (2019), for example, ground their understanding of experimental innovation in two principles: the scientific approach to experimentation and capturing customers' interests at the early stages of the innovation process. The scientific approach to experimentation is inspired by the lean start-up approach, which 'involves turning the underlying assumptions upon which a business model is built into hypotheses that can be tested through the careful use of experiments [...]' (Hampel et al., 2019, p. 1). Within this context, understanding the end-users' (e.g., customers, visitors, audiences, communities) needs, interests and concerns informs the formalisation of the hypothesis, which results in a faster innovation process, higher certainty and lower resource requirements.

Hampel et al. (2019) note that scholarship on experimental innovation is 'limited to a handful of publications to date,' which explains the ambiguity around the term, but also highlights the need for more research to unpack the essential elements and associated values of experimental innovation. Nonetheless, enabling a broad approach to experimentation can provide critical intangible infrastructure for internal 
innovation. For example, authorising individual employees to question the status quo and present possible solutions, establishing an organisational culture that encourages and recognises creativity and constructing internal collaborations between different individuals, departments or units are all crucial infrastructures for innovation.

While experimental innovation appears to have significant advantages, it can also present considerable challenges. More specifically, experimental innovation disrupts established authorities, organisational structures and allocation of resources. Those are the types of challenges that every organisation needs to investigate to rejuvenate and remain relevant; hence, they can also be viewed as opportunities for improvement and growth. Ferrier (2018) provides several strategies to address these challenges and develop an organisational culture which is conducive to experimentation. Some of these strategies include training employees on experimental methodologies, developing and promoting channels to share and review new ideas by employees, building internal communication channels to increase awareness of new technology or business trends and rewarding employees for their innovative achievements (Ferrier, 2018). To illustrate the previous discussion, I briefly examine two initiatives from the private sector that aim to adopt experimental innovation as a core organisational value.

The first initiative is Pfizer's Dare to Try programme. Pfizer, one of the world's largest biopharmaceutical companies, launched the program in 2013 to give its employees 'a comprehensive methodology to develop new ideas, take thoughtful risk through experimentation, and ignite change' (Pfizer, n.d.). Through specialised training, some employees become 'innovation champions' who permeate experimental culture and behaviour among their teams.

The second initiative is 3M's initiative 15\% Culture, which allows employees to spend $15 \%$ of their time experimenting with new ideas or projects of their choice. 'FlexAbility,' 'Mentoring' and '15\% Culture' make the three core elements of 3M's organisational culture. To highlight the role of experimentation, $3 \mathrm{M}$ states on its website: 'Whether it's experimenting with a new technology, forming a special interest group around a fresh idea or finding a new way to run a process, our 15\% Culture gives employees in all areas the license to innovate' (3M, n.d.). The idea of giving employees the time and, more importantly, the 'license to innovate' is crucial to building an effective experimental innovation model. Later in this chapter, I will discuss how public organisations can adopt a similar concept, an 'authorising environment,' coined by Seb Chan, chief experience officer at the Australian Centre for the Moving Image (ACMI) in Melbourne.

The two initiatives at Pfizer and $3 \mathrm{M}$ give a brief overview of how experimental innovation is implemented at two world-leading companies in the area of innovation. Although experimental innovation is a relatively new concept, as discussed previously, it has attracted many museums around the world. The implementation model, however, varies from one museum to another. This variation is expected considering the lack of a structured understanding of experimental innovation and the unique character for each museum in terms of its collections, size, governing body, organisational structure and audiences. The remainder of this 
chapter explores and analyses examples of experimental innovation models in museums in Australia, the United States and the United Kingdom.

\section{Institutionalisation of experimental innovation in museums}

For museums (or any organisation) to achieve any degree of innovation, they must promote creativity, imagination and out-of-the-box thinking among their employees. That requires an organisational structure that nurtures, encourages and rewards experimentation as an essential part of the innovation process. In that sense, adopting experimentation as a core organisational value, as argued here, is crucial to building a successful museum innovation model. That should be manifested in the museum's DNA, including its mission, policies, procedures and how the museum leadership articulates the culture of experimentation in its messages to museum employees, external collaborators and the community. Therefore, a close analysis of the museum's organisational structure can indicate the readiness of the museum to adopt experimental innovation.

The Grant Museum of Zoology, which is part of the University College London (UCL) in the United Kingdom, advertises itself as an experimental testbed (Ashby, 2018). In his article, 'Museums as experimental test-beds: Lessons from a university museum,' Ashby (2018) stresses the importance of establishing an experimental philosophy and communicating this philosophy with everyone involved with the museum:

The decision for the Grant Museum to work at being an experimental museum was a deliberate one - we actively set about seeking research partnerships and made projects very visible from the outset, so that other potential academic collaborators saw that we were open to proposals. We even designed the new museum space with this kind of work in mind.

(Ashby, 2018, p. 6)

As Ashby states, experimentation needs to be intentional and reflected in all aspects of museum work, including how it chooses its partners and designs its internal space. Additionally, Ashby emphasises how the Grant Museum continuously reiterated its experimental philosophy to the world:

The first thing we did, and continue to do, is say that we are an experimental test-bed. Every time we get in front of a museum or a Higher Education audience, or whenever we write a practice-based journal article or press release, we say that we want to act as an experimental testbed. Such repetition of the message is key to getting the idea ingrained in stakeholders' opinion of you. 
The quote illustrates Ashby's belief in the power of consistent messaging, both internally (to museum employees) and externally (to museum constituents), to activate and confirm experimentation as a core museum value. Moreover, Ashby (2018) gives special emphasis to the role of top museum administration, arguing that 'strategic plans and senior management's communications need to reflect the philosophy [of experimentation] if a museum's staff - and ideally its audiences are to believe that they are an experimental test-bed' (Ashby, 2018, p. 6).

By doing so, the museum leadership provides the staff with 'the license to innovate' and encourages them to adopt experimentation in their daily work. Seb Chan concurs with Ashby and adds that the museum leadership needs to give employees 'a sense of responsibility [over the experimentation process] and trust that they will use it responsibly' (Chan, 2019). Chan calls it an 'authorising environment,' where employees are given the green light to experiment with new solutions and try novel approaches. This authorising environment is paramount to experimental innovation, which is one of five core value at ACMI. In its annual report, ACMI states: 'Innovation requires experimentation and risk-taking. We enable a culture that embraces creative risk-taking, supporting bold ideas and new voices with energy and commitment' (ACMI, 2019). The ACMI case will be discussed further below.

In a U.S.A. context, one of the most known museums for adopting experimental innovation across their organisational structures is the Crystal Bridges Museum of American Art in Arkansas. In fact, Crystal Bridges is the only museum I know of that has an employee position titled 'creative director of experimentation and development.' This position is currently occupied by Shane Richey, who has been with the museum in different roles, including web designer and digital media manager, since 2009. Richie states, 'Crystal Bridges is interested in the convergence of art and innovation, but there's a balance to be found when using experimentation to add value to our purpose' (Crystal Bridges, 2019).

Richey's background as a web designer and digital media expert seems to shape the experimental innovation model at Crystal Bridges, which is centred around technology. However, Richey confirms that ' $[\mathrm{t}]$ he goal is not technology for technology's sake, but looking for new tools that we can use to bring the public closer to art' (Crystal Bridges, 2019). To keep all staff members engaged and thinking creatively beyond digital, the museum carved out a space in the Early American Art Gallery, called 'The Niche,' which serves as an experimental lab to explore new exhibition or content ideas by anyone in the museum (Harmon, 2019). Richey underscores the significance of The Niche: 'The best way to empower museum staff is to allow them to have ideas and make them feel like they have the ability to pursue those ideas even if you as a leader are not sure about them' (quoted in Harmon, 2019, n.p.); and The Niche is a practical way to do just that. It gives the museum staff the 'license' or 'authorising environment' to run their experimentation. In summary, the institutionalisation of experimental innovation at Crystal Bridges is manifested in a dedicated position, a rare finding in museums, and also in an experimental space that is available for any museum staff member to explore new ideas. 
In a report for the Washington Post titled 'Experimentation is key to success for National Portrait Gallery's director,' Kim Sajet, director of the National Portrait Gallery, explains how experimentation has been a cornerstone in her leadership style: 'I'm very much about experimentation. I came in and said, "You know, nothing is a sacred cow. Let's look at breaking down the hierarchies, experimenting and piloting things"' (quoted in McGlone, 2015, n.p.). The National Portrait Gallery is located in Washington, DC, and is part of the Smithsonian Institution. As a manifestation of Sajet's strategy, the museum challenged established curatorial practices and the traditional definition of portrait art by commissioning Cuban American artist Jorge Rodriguez-Gerada to create a six-acre landscape portrait on the National Mall in Washington, DC, midway between the World War II Memorial and the Lincoln Memorial. Approximately 2,000 tons of sand, 800 tons of soil, 10,000 wooden pegs, miles of string and assistance from GPS topography poles (which allows the materials to be placed with precision) have been used to create the portrait. This experimentation does not only expand the understanding of what constitutes a portrait but also inspires a more in-depth discussion about issues related to race, which is one of the issues that Sajet was interested in investigating through the National Portrait Gallery (McGlone, 2015). Titled 'Out of Many, One,' the portrait depicts the face of a young man with multiracial features. The face was inspired by many pictures of ordinary Washingtonians taken by Rodriguez-Gerada, reflecting the diversity of American communities.

The previous discussion illustrates the different strategies by which museums have attempted to institutionalise experimental innovation. Through establishing an 'experimental philosophy,' as is the case in The Grant Museum of Zoology (U.K.), or by providing an 'authorising environment,' as Chan describes it at ACMI (Australia), or, perhaps, through creating an official museum position for 'Experimentation and Development,' as seen at Crystal Bridges Museum of Art (U.S.A.), or by challenging current curatorial practises, as is the case at the National Portrait Gallery, many museums across the world have realised the significance of adopting experimental innovation and have taken serious steps to make sure it is embedded in their daily work.

Yet, how is experimental innovation implemented and practised in museums? A key approach is to apply the concepts of design thinking (DT) and, more recently, accelerated design thinking (ADT). To answer how experimental innovation strategies are turned into practices it is important to explore the DT and the ADT approaches and analyse their connection to experimentation and ADT. The analysis is illustrated by investigating a recent project to re-create an audio guide for the Scorsese exhibition at the Australian Centre for the Moving Image (ACMI) in Melbourne.

\section{Adopting an accelerated design thinking (ADT) approach}

The concept of design thinking was developed in the late 1950s and early 1960s by design engineers (see, for example, Clancey (2016) on the work of John Edward 
Arnold on 'creative engineering') as a novel approach to use creativity in solving complex problems. Through a defined but interactive, non-linear process, design thinking strives to understand the user/audience/constituent, challenge current assumptions and redefine problems to develop innovative solutions. Rooted in political economy, democracy and feminism frameworks, the Scandinavian countries developed critical, user-led design approaches in the 1970s, intending to empower end-users (Stuedahl, 2018).

More recently, design thinking has gained popularity in the museum and cultural heritage sectors (see, for example, MacLeod et al., 2015; Silver et al., 2013) for its human-centric approach. More specifically, a five-step model empathise, define, ideate, prototype and test - was introduced by Stanford University Hasso Plattner Institute of Design (commonly known as the d.school); and the model has become the standard framework for design thinking in many organisations, including museums. It is worth noting though that while DT helps engage the end-user and reach more reliable results, the entire process can be time-consuming. Additionally, the fast development in technology, marketplace volatility and the rise of personalisation in products, services, marketing and customer experience, which all require a more agile innovation strategy, have compelled many companies in the private sector to adopt an accelerated design thinking (ADT) approach.

In the same vein, similar factors to the ones mentioned above compel social organisations (including museums) to develop a more accelerated approach to design thinking as a vehicle for innovation (Mabogunje et al., 2019). It is argued here that ADT seems to be one of the appealing strategies to achieve that goal, as the following example illustrates.

ACMI Labs, self-described as the unit responsible for 'experiments in media, technology \& user experience' at the ACMI is known for having a leadership that values and drives innovation. Its chief experience officer states:

For most of the practice here and in my previous roles, [it] was about creating a space where experimentation, which is perceived as risky, is embraced. And that means authorising people to do things and take responsibility for things [...] not working and give them the space and sometimes the protection to do that.

(Chan, 2019)

I discussed earlier the importance of creating an 'authorising environment' to encourage experimentation. Building on that discussion, let us explore how this environment, along with adopting the ADT approach, can improve innovation in the museum context. In 2015, when ACMI was about to receive a travelling exhibition on Martin Scorsese, the iconic American film director, producer and actor, Chan and Lucie Paterson, heads of experience, product and digital at ACMI, thought the accompanying audio guide was not suitable for ACMI audiences, and they wanted to do something about it: 
We are buying an exhibit that has an audio guide. We could have just taken the audio guide, but between Lucie and me, we thought that [the audio guide] kind of sucked, and it was an opportunity for experimentation. It was Lucie's job to transform it into something that sucked-less. That's a very small thing, but it was very significant.

(Chan, 2019)

Paterson explains: 'It was all in French [...]. You kind of just listened to a narrative, and there wasn't much connection to what you were looking at in the exhibition' (Paterson, 2019). Paterson, in this instance, utilised her expertise on museum experience, empathising with the potential exhibit audiences. This reflects Naiman's description of design thinkers as they 'rely on customer insights gained from realworld experiments, not just historical data or market research' (Naiman, 2019).

With almost no budget, Paterson experimented with a few options to improve the audio guide. In collaboration with ACMI curators, the team identified 15 stops throughout the exhibition to place the audio narrative and added another layer of interpretation by including a written transcription of the audio to make the experience accessible to wider audiences. Information about personal items given by Scorsese from his house or his studio for this specific exhibition was also added to the narrative. After several iterations, the audio guide was tested internally (with people who were not involved in the project). Additionally, the small team conducted interviews with visitors and observed audience reactions, which led to further small but essential improvements in the design of the audio guide itself and the overall service design of the product from end to end (Paterson, 2019).

Notably, this short experimentation had a broad impact on the creation of museum audio guides inside and outside ACMI. Chan (2019) uncovers that the same codebase was repurposed for the Wallace and Gromit exhibition the following year - which saved us effort and allowed us to focus those energies on content creation instead' (Chan, 2019). Additionally, ACMI Labs made the source code for the audio guide available on GitHub, a hosting platform for software development. Andrew Serong, Web \& Software Developer at ACMI, wrote a special blog on the open platform Medium, explaining different technical aspects of the code and how it can be forked at other organisations (Serong, 2016). Records show that at least five other institutions in five different countries have used the code for their internal audio guides, including Vila Itororó in São Paulo, Brazil, the Immigration Museum (part of Museum Victoria) in Melbourne, Australia, the National Galleries of Scotland, the Museum of Contemporary Art in Panamá and the Kalmar läns Museum in Kalmar, Sweden.

A close analysis of the Scorsese audio guide project reveals that the ADT approach was implemented to guide the incremental innovation process, as follows:

1. Empathise: understanding the significance of engagement in the museum experience. Paterson and Chan empathised with potential visitors of the exhibit and understood that improvements are needed. 
2. Define: the exhibit audio guide was in French with no direct connections to the objects on display. Therefore, the design challenge was to add an audio guide in English and link the narrative to specific objects in the exhibition.

3. Ideate: working with the museum curators, the team brainstormed ideas to improve the audio guide.

4. Prototype: the new engaging audio guide was developed.

5. Test: the audio was tested internally and externally before launching. It was also connected to Google Analytics to assess its effectiveness during the exhibition.

As a reminder, ADT aims to fast-track (not eliminate) the design process. In the case of the Scorsese audio guide, we can identify the intersection of experimental culture and ADT, which leads to a more nimble and agile innovation model. Some researchers refer to this phenomenon as 'post-agility' (Baskerville et al., 2011). If Paterson and Chan had to face complicated administrative structures to address the issue, the entire project could have been killed at an early stage. Remember that Chan and Paterson did not have to add another project to their full work schedule. Many other museums would have probably accepted the original audio guide. But because Chan and his team adopted an ADT approach coupled with an organisational culture that nurtures and encourages experimentation, the team was motivated to identify the problem and offer a swift and creative solution. Therefore, it is essential to note here that creativity and experimental mindset for museum employees, along with conducive organisational culture, are important factors in encouraging these types of incremental innovations to take place.

\section{Embracing failure}

Not all experiments succeed. Therefore, creating a culture in the museum that embraces failure and considers it an opportunity for learning and growth is an essential prerequisite for experimental innovation. This belief is shared among all innovative institutions and leaders. Jeff Bezos, founder and CEO of Amazon states:

One area where I think we are especially distinctive is failure. I believe we are the best place in the world to fail (we have plenty of practice!), and failure and invention are inseparable twins. To invent you have to experiment, and if you know in advance that it's going to work, it's not an experiment. Most large organisations embrace the idea of invention, but are not willing to suffer the string of failed experiments necessary to get there.

(Bezos, 2016)

In this quote, Bezos eloquently unpacks the connection between failure, experimentation and innovation. They are interconnected and interdependent. Shying 
away from failure (and experimentation) is a strategy that leads to a stagnant, idle work environment. In contrast, innovative museums build a culture that encourages experimentation and accepts failure. I had an extensive discussion with Seb Chan in 2014 when he was the director of the Digital \& Emerging Media Department at Cooper Hewitt, Smithsonian Design Museum in New York City about innovation in museums. We ended up spending a considerable amount of our time talking about failure, how it is perceived and dealt with in museums. Chan had strong views on this specific issue - some of these views are common beliefs in the innovation community, but others can be seen as a little provocative. Chan asserts:

I am a firm believer that failure is instructive. One of the reasons we invested so heavily in in-house expertise at Powerhouse (and now, increasingly at Cooper-Hewitt), is that it allowed for lots of small, inexpensive failures, and the cultivation of more of a culture of experimentation and continuous improvement.

(Chan, 2014)

Chan actively promotes this message to his team. Micah Walter and Aaron Cope, who were part of Chan's digital team at Cooper Hewitt, confirm the same understanding about failure. For example, Walter (2014) states, 'we use failure to learn and build and grow. It is a necessary part of everything we do,' and Cope (2014) adds that 'if something fails, then what is important is to be able to recognise that it failed and to understand why; and to be able to speak about it.'

The previous statements are in line with the conventional wisdom among innovation experts. What is probably a provocative but sensible proposition is Chan's idea of the need to fail publicly. Sharing failures with the public may seem as undesirable strategy, but Chan sees it in a different light:

If it all happens behind closed doors, the only criticism you will get is from the people who are already doing it a particular way. If you fail publicly, you will get people who will criticise you who will say, 'I am already doing it better. Why are not you doing it like this?' You will also get supporters who say, 'Wow, that was a really interesting way of trying that. Did you think about this other way?' If it is only internal, you never get that feedback from people outside.

(Chan, 2014)

Museums may be able to avoid potential public criticism by shielding their experimentations from the public, but by doing so they also lose the potential of receiving valuable feedback and creative ideas from external sources. Creating channels by which creative ideas can move into and outside the organisation is known as open innovation (Eid, 2016, 2019). Chan values open innovation and 
argues that 'the open part is that it has to be open publicly. If it is not open publicly, you do not get the benefit of the world criticising your work' (Chan, 2014).

As part of its ethics, standards and professional practices standards, American Alliance of Museums (n.d.) emphasises that maintaining public trust is crucial to museums. Sharing failures with the public can be perceived as a trigger to sabotage public trust, a fear that leads many museums to keep the outcomes of their experimentation (especially failed ones) internally. This is a legitimate concern. However, the failures to which Chan refers are not spectacular ones and will arguably not lead to losing public trust. Quite the contrary, transparency and getting the public involved is an effective strategy that builds public trust.

Another concern that prevents some museums from publicly sharing their failures is the fear of missing out on funding opportunities and donations (if they are perceived as incompetent). Chan (2014) refutes that notion and argues:

I would say though that the proof in my work is that has not been the case; in fact, it has resulted in millions of dollars coming to this [Cooper Hewitt] museum. And in the case of the Powerhouse, millions of dollars came through new government projects and visitor action. You have got to trust that that is going to happen. It is not going to happen for everyone, and it is not always going to work for me. But I think there is a reasonably - at least in our case here - a clear line between our experimentation and literally millions of dollars of funding.

(Chan, 2014)

The opportunity to willingly share failures with the public and attract valuable feedback from external sources might work in the nonprofit world. This is a great advantage that the museum sector enjoys, which makes the innovation ecosystem more diverse and dynamic. Sectoral innovation ecosystem can be defined as a set of complex relationships between key actors, networks, institutions and technologies (Malerba, 2005). Actors may include individuals (such as curators, artists, administrators, technologists, educators and audiences) and organisations (such as museums, universities, associations, corporations and nonprofits). What is apparent is that there is a plethora of innovative ideas, skills and expertise outside any individual museum. And those museums that can attract and capitalise on external ideas and expertise will be able to advance their museums. Overall, each museum may have to decide the degree of openness and transparency with their internal experimentation, balancing between the need to fail publicly and maintaining public trust. What is certain, though, is that accepting failure as part of the creative process is essential to building an effective experimental innovation model in any museum.

\section{Conclusion}

The fast development in technology and the increased expectations of museums to take a larger role in addressing contemporary social and environmental issues are 
compelling many museums to develop a more innovative and agile approach to their work. In an attempt to respond to these challenges, many museums around the world are adopting experimental innovation, an emerging framework that promotes the use of experimentation across all organisational units and levels. This chapter has documented that experimental innovation models vary from one museum to another. From establishing an 'experimental philosophy' and presenting itself as an 'experimental test-bed,' to building an 'authorising environment,' where experimentation is encouraged (and possible failure is accepted) and instituting a dedicated position (such as director of experimentation and development) for experimentation, each museum is carving out its individual strategy to encourage experimentation as part of its daily practices. Overall, establishing an organisational culture that promotes experimentation and encourages museum staff to test their creative ideas helps museums achieve their missions more effectively.

\section{Bibliography}

3M. (n.d.). $3 M$ Careers. https://www.3m.com/: https://www.3m.com/3M/en_US/ careers-us/working-at-3m/life-with-3m/

ACMI. (2019, August). 2018-2019 Annual report. https://acmi.s3.amazonaws.com/media/ uploads/files/Annual_Report_2018-19.pdf?Signature=drfhUKSWKiqr6Z83aqBE6stodMw \%3D\&AWSAccessKeyId=AKIAJJOVMAJPAFURBISA\&Expires=1577766326

American Alliance of Museums. (n.d.). Public trust and accountability standards. https://www. aam-us.org/programs/ethics-standards-and-professional-practices/public-trust-andaccountability-standards/

Ashby, J. (2018). Museums as experimental test-beds: Lessons from a university museum. Journal of Natural Science Collections, 5, 4-12. https://www.natsca.org/article/2435

Baskerville, R., Pries-Heje, J., \& Madsen, S. (2011). Post-agility: What follows a decade of agility? 11th International Conference on Agile Software Development, XP2010 (pp. 543-555). Trondheim, Norway: Elsevier.

Bezos, J. (2016). Letter to shareholders. https://www.sec.gov/Archives/edgar/data/1018724/ 000119312516530910/d168744dex991.htm

Brooklyn Museum of Art. (2019, November). About the museum. https://www. brooklynmuseum.org/about

Chan, S. (2014). Interview with Seb Chan, Director of Digital \& Emerging Media Department at Cooper Hewitt, Smithsonian Design Museum. (H. Eid, Interviewer).

Chan, S. (2019, July). Interview with Seb Chan, Chief Experience Officer at the Australian Centre for the Moving Image in Melbourne, Australia. (H. Eid, Interviewer).

Clancey, W. J. (2016). Creative engineering: Promoting innovation by thinking - John E. Arnold. Stanford Digital Repository. https://stacks.stanford.edu/file/druid:jb100vs5745/ Creative\%20Engineering\%20-\%20John\%20E.\%20Arnold.pdf

Cope, A. (2014). Interview with Aaron Cope, Digital \& Emerging Media Department at Cooper Hewitt, Smithsonian Design Museum. (H. Eid, Interviewer).

Crystal Bridges. (2019, 23 January). From space travel to augmented reality: Crystal Bridges looks for new ways to innovate. https://crystalbridges.org/blog/from-space-travel-toaugmented-reality-crystal-bridges-looks-for-new-ways-to-innovate/ 
Eid, H. (2016). The museum innovation model: A museum perspective on innovation. Museums and the Web (pp. 261-276). https://mw2016.museumsandtheweb.com/paper/ the-museum-innovation-model-a-museum-perspective-to-innovation/

Eid, H. (2019). Museum innovation and social entrepreneurship: A new model for a challenging era. Routledge.

Ferrier, A. (2018, 15 March). Increasing experimentation and autonomy capability: The new corporate innovation imperative. Innovation Management. https://innovationmanagement. se/2018/03/15/increasing-experimentation-and-autonomy-capability-the-newcorporate-innovation-imperative/

Hampel, C., Perkmann, M., \& Phillips, N. (2019). Beyond the lean start-up: Experimentation in corporate entrepreneurship and innovation. Innovation, 22, 1-11. 10.1080/14479338. 2019.1632713

Harmon, E. (2019, 30 January). The spaceship solution: How museums can use experimental technology to solve problems. American Alliance of Museums. https://www.aamus.org/2019/01/30/the-spaceship-solution-how-museums-can-use-experimentaltechnology-to-solve-problems/

IC3. (n.d.). Methodology. https://ic-3.com/methodology/

Mabogunje, A., Sonalkar, N., \& Leifer, L. (2019). Redesigning social organization for accelerated innovation in the new digital economy: A design thinking perspective. In C. Meinel \& L. Leifer (Eds.), Design thinking research looking further: Design thinking beyond solution-fixation (pp. 143-156). Springer. https://link.springer.com/chapter/10.1007/ 978-3-319-97082-0_8

MacLeod, S., Dodd, J., \& Duncan, T. (2015). New museum design cultures: Harnessing the potential of design and 'design thinking' in museums. Museum Management and Curatorship, 30(4), 314-341.

Malerba, F. (2005). Sectoral systems of innovation: A framework for linking innovation to the knowledge base, structure and dynamics of sectors. Economics of Innovation and New Technology, 14(1-2 Microeconomics and Innovation), 63-82.

McGlone, P. (2015, 15 October). Experimentation is key to success for National Portrait Gallery's director. Washington Post. https://www.washingtonpost.com/entertainment/ museums/experimentation-is-key-to-success-for-national-portrait-gallerys-director/ 2015/10/15/7ab5dbae-6b8e-11e5-9bfe-e59f5e244f92_story.html

Naiman, L. (2019). Design thinking as a strategy for innovation. The European Business Review. https://www.europeanbusinessreview.com/design-thinking-as-a-strategy-forinnovation/?_cf_chl_jschl_tk__=baacc81bfff727d4189fdcf9b29c2919371a55341577404709-0-AZu2SkGXaNRHvMOMSTHebgYT5scvZeZGzpcqJ0ptLG0VkB_ gElWwX6VAJ6xqhel7YzGCi5YWrLLX8of8HeHnzylH7Nva9_aT

Paterson, L. (2019, July). Interview with Lucie Paterson, Head of Experience, Product \& Digital at the Australian Centre for the Moving Image (ACMI). (H. Eid, Interviewer).

Pfizer. (n.d.). Culture matters: Building on our OWNIT! culture. https://www.pfizer. com/files/investors/financial_reports/annual_reports/2014/business_colleagues.htm

Schmitt. (2016, October 7). Reinventing R\&D for the age of innovation. Inovo. https:// www.theinovogroup.com/reinventing-rd-for-the-age-of-innovation/

Serong, A. (2016, 30 May). An open source museum audio guide. Medium. https://labs. acmi.net.au/an-open-source-static-museum-audio-guide- $4 \mathrm{c} 5 \mathrm{~cd} 83 \mathrm{dbdcb}$

Silvers, D. M., Wilson, M. W., \& Rogers, M. (2013). Design thinking for visitor engagement: Tackling one museum's big challenge through human-centered design. Museums and the Web 2013. Portland, OR. https://mw2013.museumsandtheweb.com/ paper/design-thinking/ 


\section{Haitham Eid}

Stuedahl, D. (2018). Participation in design and changing practices of museum development. In K. Drotner, V. Dziekan, R. Parry, \& K. C. Schroder (Eds.), The Routledge handbook of museums, media and communication. Routledge.

The Center for Social Innovation. (n.d.). Defining social innovation. https://www.gsb. stanford.edu/faculty-research/centers-initiatives/csi/defining-social-innovation

Visser, J. (2017). The museum as center for social innovation. History News, 72(1), pp. 9-13. https://visschstam.com/files/2017-07/visser-with-cover-toc.pdf

Walter, M. (2014). Interview with Micah Walter, Digital \& Emerging Media Department at Cooper Hewitt, Smithsonian Design Museum. (H. Eid, Interviewer). 